ANDRADE JÚNIOR, V.C.; YURI, J.E.; NUNES, U.R.; PIMENTA, F.L.; MATOS, C.S.M.; FLORIO, F.C.A.; MADEIRA, D.M. Emprego de tipos de cobertura de canteiro no cultivo da alface. Horticultura Brasileira, Brasília, v.23, n.4, p.899-903, out-dez 2005.

\title{
Emprego de tipos de cobertura de canteiro no cultivo da alface
}

\author{
Valter C. de Andrade Júnior ${ }^{1,4}$; Jony E. Yuri ${ }^{2}$; Ubirajara R. Nunes ${ }^{1}$; Fernando L. Pimenta ${ }^{3}$; Christiano de \\ S.M. de Matos $^{3}$; Francisco C. de A. Florio ${ }^{3}$; Dermival M. Madeira ${ }^{3}$ \\ ${ }^{1}$ Faculdades Federais Integradas de Diamantina, FCA, Depto. Agronomia, R. da Glória, 187, Centro, 39100-000 Diamantina-MG; \\ ${ }^{2}$ UFLA, DAG, C. Postal 37, 37200-000 Lavras-MG; ${ }^{3}$ Universidade Vale do Rio Verde, UNINCOR, Av. Castelo Branco, 82, Centro, \\ 37410-000Três Corações-MG; ${ }^{4}$ E-mail: valterjr@fafeid.edu.br
}

\section{RESUMO}

Com o objetivo de avaliar o efeito de diferentes coberturas de canteiro sobre as características agronômicas de cultivares de alface (Lactuca sativa L.) tipo lisa, foi realizado um experimento na Universidade Vale do Rio Verde em Três Corações (MG). O delineamento experimental utilizado foi de blocos ao acaso em esquema fatorial $5 \times 2$, proveniente da combinação de cinco tipos de cobertura (plástico preto, capim braquiária seco, casca de arroz, casca de café e solo nu) e duas cultivares de alface tipo lisa (Regina e Elisa), com 3 repetições. A colheita foi realizada 42 dias após o transplantio, sendo avaliados a produção total $\left(\mathrm{t} \mathrm{ha}^{-1}\right)$, produção comercial, massa média por planta, diâmetro médio de cabeça, diâmetro médio de caule, número médio de folhas e massa média de raiz. Foi observada interação significativa entre tipos de cobertura $\mathrm{x}$ cultivares somente para a característica massa média de raiz, tendo a cultivar Elisa apresentado maior massa média de raiz quando utilizadas as coberturas com casca de café e casca de arroz. A cobertura com casca de café foi a que proporcionou os melhores resultados, superando os demais tipos de cobertura para todas as características avaliadas. A cultivar Regina foi superior à Elisa em quase todas as características estudadas, exceto para diâmetro médio de caule onde não foi observada diferença significativa entre as cultivares. 'Elisa' também apresentou maior massa média de raiz que a cultivar Regina.

Palavras-chave: Lactuca sativa L., coberturas de solo, produção.

\begin{abstract}
Evaluation of mulch types on lettuce production

An experiment was carried out at Universidade Vale do Rio Verde, Minas Gerais State, Brazil, to evaluate the effect of bed coverages on the agronomic characteristics of lettuce cultivars. The experimental design was of randomized complete blocks in a $5 \times 2$ factorial scheme with five types of mulch (black plastic; dry braquiaria grass; rice husk; coffee husk and nude soil), two leaf lettuce cultivars (Regina and Elisa) and three replications. Plants were harvested 42 days after the transplanting date. The total and commercial yield, average fresh plant plant weight, head average diameter, stem average diameter, leave average number and the root fresh weight were evaluated. Only for the root average weight was observed significant interaction between coverage types and cultivars. The $\mathrm{cv}$. Elisa presented the highest root average weight when the coffee or rice husk were used. The coffee husk proportioned the best results. This coverage exceeded all others in all the evaluated characteristics. The cv Regina was superior to Elisa in almost all studied characteristics, except in stem average diameter where no significant difference was detected between cultivars. 'Elisa' presented higher root weight than 'Regina'.
\end{abstract}

Keywords: Lactuca sativa L., soil coverages, yield.

\section{(Recebido para publicação em 22 de julho de 2004 e aceito em 3 de agosto de 2005)}

$\mathrm{N}^{a}$ região sul de Minas concentrase grande número de produtores de alface, os quais, em sua maioria, utilizam algum tipo de material como cobertura de canteiro. Entretanto, existe pouca informação sobre os materiais disponíveis na região e que podem ser utilizados como cobertura de solo.

Tanto a cobertura com plástico quanto com restos vegetais têm sido exploradas com os objetivos de reduzir a $e v a-$ poração da água na superfície do solo; diminuir as oscilações de temperatura do solo (ARAÚJO et al., 1993); permitir o controle de plantas invasoras; oferecer proteção aos frutos, evitando seu contato direto com o solo; obter maior precocidade da colheita e capacidade de influir diretamente, de maneira positiva, sobre a incidência de pragas e doenças (CASTELLANE, 1995). Os restos vegetais contribuem ainda como reserva considerável de nutrientes, cuja disponibilização pode ser rápida e intensa, dependendo, dentre outros fatores, do regime de chuvas (ROSOLEM et al. 2003); da relação $\mathrm{C} / \mathrm{N}$ (ROBINSON, 1988) além de reduzir a lixiviação dos nutrientes e a compactação do solo.

Avaliando a utilização de materiais como cobertura morta do solo no cultivo de pimentão, Queiroga et al. (2002) verificaram que o diâmetro, número, massa de fruto e a produção foram afetados pela cobertura morta, sendo a palha de carnaúba superior aos demais materiais usados como cobertura. Segundo os autores, este fato deve-se à melhor conservação da umidade do solo, menor incidência de plantas daninhas, redução da temperatura do solo e ao for- necimento de nutrientes às plantas, devido a sua rápida decomposição.

Ao avaliar o efeito da cobertura morta sobre o comportamento de cultivares de alface no município de Mossoró, Maia Neto (1988) verificou que a cobertura morta proporcionou aumentos na produção e na massa média de plantas das cultivares Brasil 221, Babá de Verão e Vitória, e também reduziu a massa de matéria fresca das plantas invasoras.

De acordo com Reghin et al. (2002), o uso da cobertura com agrotextil preto proporcionou maior produção de alface (cv. Veneza Roxa) quando comparado à cobertura com palha de arroz, $(153,68$ g e $127,71 \mathrm{~g}$, respectivamente). A palha de arroz picada não apresentou resposta favorável como cobertura de canteiro, pois permitiu o desenvolvimento de 
várias espécies de plantas daninhas. Já o agrotextil preto foi eficiente no controle de plantas daninhas, promovendo melhor desenvolvimento e produção de plantas com maior massa. Tanto o uso da palha de arroz quanto solo nu resultaram em decréscimo na massa fresca da cabeça de 18,12 e 13,62\%, respectivamente, em relação ao agrotextil preto. Provavelmente, a presença de plantas daninhas interferiu na formação e na massa fresca da cabeça de alface.

No cultivo da alface, Andreani Júnior e Galbiati Neto (2003) avaliaram a influência de vários tipos de cobertura de solo sobre a produtividade e verificaram que as coberturas com bagaço de cana e palha de arroz proporcionaram maiores ganhos de peso das plantas, 710,0 e 669,5 gramas, respectivamente, quando comparada ao tratamento terra nua sem capina $(355,6 \mathrm{~g})$ e ao tratamento em que se utilizou plástico transparente $(280,4 \mathrm{~g})$.

A utilização da cobertura de solo no cultivo da alface tem se mostrado fator determinante no aumento da produção e na qualidade do produto. No entanto, para que a utilização da cobertura seja viável é preciso que novas alternativas de cobertura, disponíveis na região de cultivo, sejam avaliadas.

Este trabalho teve como objetivo avaliar os efeitos de diferentes tipos de cobertura de canteiro sobre a produção e qualidade de duas cultivares de alface tipo lisa.

\section{MATERIAL E MÉTODOS}

$\mathrm{O}$ experimento foi realizado no $\mathrm{Se}$ tor de Olericultura da Universidade Vale do Rio Verde (UNINCOR), Três Corações, MG, de 24/09 a 05/12/2003. O clima, de acordo com a classificação de Koppen, é Cwb, ou seja, temperado chuvoso, com temperatura média do mês mais quente inferior a $22^{\circ} \mathrm{C}$. O solo predominante na área é classificado como Latossolo Vermelho distroférrico, textura argilosa com características: $\mathrm{pH}$ $\mathrm{H}_{2} \mathrm{O}: 5,5 ; \mathrm{P}$ disponível $=1,2 \mathrm{mg} / \mathrm{dm}^{3} ; \mathrm{K}$ disponível = $22 \mathrm{mg} / \mathrm{dm}^{3} ; \mathrm{H}+\mathrm{Al}^{3+}=5,0$ $\mathrm{mg} / \mathrm{dm}^{3} ; \mathrm{Al}^{3+}=0,2 \mathrm{cmol} / \mathrm{dm}^{3} ; \mathrm{Ca}^{2+}=$ $2,9 \mathrm{cmol}_{\mathrm{c}} / \mathrm{dm}^{3} ; \mathrm{Mg}^{2+}=1,9 \mathrm{cmol} / \mathrm{dm}^{3}$; $\mathrm{SB}=4,9 \mathrm{cmol}_{\mathrm{c}} / \mathrm{dm}^{3} ; \mathrm{CTC}=9,9 \mathrm{cmol}_{\mathrm{c}} /$ $\mathrm{dm}^{3} ; \mathrm{MO}=2,4 \mathrm{~g} / \mathrm{dm}^{3}$.
O delineamento experimental utilizado foi em blocos ao acaso em esquema fatorial $5 \times 2$, proveniente da combinação de cinco tipos de coberturas de canteiro: [Brachiaria decumbens (capim braquiária seco); Oryza sativa L. (casca de arroz); Coffea arabica L. (casca de café); plástico preto com densidade de 50 micra e testemunha (sem cobertura)] e duas cultivares de alface tipo lisa (Regina e Elisa), com 3 repetições.

As mudas foram produzidas sob estufa plástica em bandejas de isopor de 128 células contendo substrato artificial Plantimax ${ }^{\circledR}$ e transplantadas 30 dias após a semeadura, em canteiros com $1,25 \mathrm{~m}$ de largura e $20 \mathrm{~cm}$ de altura, espaçados $30 \mathrm{~cm}$ um do outro. Foram utilizadas 5 fileiras por canteiro, sendo as parcelas compostas por 25 plantas, espaçadas $0,25 \mathrm{~m}$, totalizando $1,56 \mathrm{~m}^{2}$ por parcela. Foi utilizada como área útil as nove plantas centrais de cada parcela, ocupando área de $0,56 \mathrm{~m}^{2}$. Antes do transplante os canteiros receberam as coberturas orgânicas que apresentavam espessura de aproximadamente $5 \mathrm{~cm} \mathrm{e}$ a cobertura com plástico preto. Os canteiros foram preparados manualmente e durante o preparo foram aplicados 200 $\mathrm{g} \mathrm{m}^{-2}$ de calcário dolomítico. A adubação de plantio foi com composto orgânico na dose de $40 t$ ha $^{-1}$, não sendo utilizada nenhuma formulação química.

Aos 25 dias após o transplantio foi realizada adubação em cobertura com a formulação 20-00-20, na dose de $60 \mathrm{~kg}$ $\mathrm{ha}^{-1}$. Foram realizadas capinas manuais nas parcelas onde ocorreram infestações com plantas daninhas e a irrigação foi feita diariamente. A irrigação foi realizada por aspersão elevando-se o teor de água no solo próximo à capacidade de campo, durante todo o ciclo da cultura. Não houve necessidade de aplicação de defensivos para o controle de pragas e doenças.

A colheita foi realizada 42 dias após o transplantio, sendo avaliadas características de produção e de qualidade das plantas. A produção total foi obtida pela soma da massa total da parte aérea de todas as plantas da área útil de cada parcela, sendo expressa em $\mathrm{t} \mathrm{ha}^{-1}$. A produção comercial foi determinada após a retirada das folhas externas que apresentavam coloração amarela ou algum tipo de injúria. Depois procedeu-se a soma da massa comercial de todas as plantas da área útil de cada parcela, sendo também expressa em $\mathrm{t} \mathrm{ha}^{-1}$. A massa média por planta foi obtida dividindo-se a massa total das plantas pelo número total de plantas da área útil da parcela, e os resultados expressos em g. O diâmetro médio de cabeça foi obtido por medição da parte mais compacta da cabeça, não considerando as folhas externas das plantas. O diâmetro médio do caule foi determinado após a colheita das plantas com raízes, sendo a medida feita logo abaixo das primeiras folhas, utilizandose um paquímetro. $\mathrm{O}$ número médio de folhas foi obtido após a obtenção de todos os dados referentes às outras avaliações. Foram retiradas todas as folhas comerciais de cada planta da parcela útil e obtido o número médio de folhas. A massa média de raiz foi obtida por pesagem do sistema radicular de todas as plantas da área útil. Foi considerado nos resultados, para todas as características avaliadas, a média das nove plantas centrais, correspondente a área útil de cada parcela.

A análise de variância foi utilizada na avaliação dos tipos de cobertura e de cultivares para as características estudadas aplicando-se o teste Scott e Knott a 5\% de probabilidade para a comparação das médias. Os dados de número médio de folhas foram transformados em $\sqrt{ } \mathrm{x}$ antes da análise, sendo apresentados nos resultados os valores das médias. As análises estatísticas foram realizadas utilizando-se o programa estatístico SISVAR (FERREIRA, 1999).

\section{RESULTADOS E DISCUSSÃO}

Foram observados efeitos significativos do tipo de cobertura do canteiro e de cultivares sobre todas as características analisadas, exceto para a característica diâmetro médio de caule, onde não foi observada diferença significativa entre as cultivares. Os resultados não evidenciaram efeitos significativos da interação tipo de cobertura x cultivar para as características avaliadas, com exceção da massa média de raiz (Tabela 1).

As produções total e comercial variaram, respectivamente, de 35,63 a $30,71 \mathrm{t} \mathrm{ha}^{-1}$ e de 70,67 a $61,59 \mathrm{t} \mathrm{ha}^{-1}$. A 
cobertura de canteiro com casca de café superou os demais tipos de cobertura em todas as características estudadas, proporcionando às cultivares produção total e comercial, massa média por planta e número médio de folhas, $77,43 \%$, $77,19 \%, 77,51 \%$ e $29,68 \%$ superiores às médias dos demais tipos de cobertura. Andreani Júnior e Galbiati Neto (2003), trabalhando com alface, não observaram diferenças significativas entre o efeito da cobertura com palha de café e plástico preto para as características peso das plantas e número de folhas. Ao avaliar diferentes tipos de coberturas de solo no desenvolvimento da alface, Verdial et al. (2001) observaram que a utilização de cobertura plástica do tipo dupla face proporcionou os maiores valores médios de produção.

No presente estudo, o material orgânico "casca de café" superou o material sintético "plástico preto" em todas as características avaliadas. Esse resultado é importante, principalmente para a região do sul de Minas, pois nesta área além de existir grande disponibilidade de casca de café também concentra-se grande número de pequenos produtores de alface.

Não foram observadas diferenças significativas entre os efeitos dos demais tipos de cobertura (capim braquiária seco, casca de arroz, plástico preto e solo sem cobertura) sobre as características estudadas, exceto para massa média por planta onde a cobertura com casca de arroz proporcionou um acúmulo de massa na planta significativamente maior que o tratamento com capim braquiária seco, plástico preto e solo sem cobertura. Para as demais características, as coberturas com capim braquiária seco, casca de arroz e plástico preto apresentaram efeitos semelhantes aos observados para o cultivo em solo sem cobertura. Portanto, no presente trabalho estes tratamentos não resultaram em benefícios para a produção. Zizas et al. (2002b) observaram que o uso de casca de arroz reduziu o peso médio das plantas da cultivar Regina. Neste mesmo trabalho o número de folhas/planta no tratamento solo sem cobertura foi significativamente menor que o verificado nas coberturas com plástico vermelho e branco, porém, não diferiu estatistica-
Tabela 1. Produção total, produção comercial, massa média por planta, diâmetro médio de cabeça, diâmetro médio de caule, número médio de folhas e massa média de raiz de duas cultivares de alface tipo lisa cultivadas em diferentes tipos de cobertura de canteiro. Três Corações, UNINCOR, 2003.

\begin{tabular}{|c|c|c|c|}
\hline \multirow{3}{*}{ Tipos de cobertura** } & \multicolumn{2}{|c|}{ Cultivares } & \multirow{3}{*}{ Média ${ }^{1}$} \\
\hline & Regina & Elisa & \\
\hline & \multicolumn{2}{|c|}{ Produção total $\left(\mathrm{t} \mathrm{ha}{ }^{-1}\right)^{\star *}-\mathrm{CV}=10,29 \%$} & \\
\hline Casca de café & 73,59 & 67,75 & 70,67 a \\
\hline Casca de arroz & 47,96 & 41,32 & $44,64 \mathrm{~b}$ \\
\hline Capim braquiária seco & 43,69 & 35,73 & $39,71 \mathrm{~b}$ \\
\hline Plástico preto & 47,77 & 30,86 & $39,32 \mathrm{~b}$ \\
\hline Solo sem cobertura & 42,78 & 28,49 & $35,63 \mathrm{~b}$ \\
\hline \multirow[t]{2}{*}{ Média1 $^{1}$} & $51,16 \mathrm{~A}$ & $40,83 \mathrm{~B}$ & \\
\hline & \multicolumn{3}{|c|}{ Produção comercial $\left(\mathrm{t} \mathrm{ha}^{-1}\right)^{* *}-\mathrm{CV}=12,13 \%$} \\
\hline Casca de café & 65,46 & 57,71 & $61,59 a$ \\
\hline Casca de arroz & 42,28 & 35,52 & $38,90 \mathrm{~b}$ \\
\hline Capim braquiária seco & 38,83 & 30,91 & $34,87 \mathrm{~b}$ \\
\hline Plástico preto & 42,22 & 26,90 & $34,56 \mathrm{~b}$ \\
\hline Solo sem cobertura & 36,92 & 24,50 & $30,71 \mathrm{~b}$ \\
\hline \multirow[t]{2}{*}{ Média $^{1}$} & $45,14 \mathrm{~A}$ & $35,11 \mathrm{~B}$ & \\
\hline & \multicolumn{3}{|c|}{ Massa média por planta $(\mathrm{g})^{* *}-\mathrm{CV}=10,25 \%$} \\
\hline Casca de café & 0,460 & 0,423 & $0,442 \mathrm{a}$ \\
\hline Casca de arroz & 0,300 & 0,258 & $0,279 b$ \\
\hline Capim braquiária seco & 0,273 & 0,223 & $0,248 \mathrm{c}$ \\
\hline Plástico preto & 0,299 & 0,193 & $0,246 \mathrm{c}$ \\
\hline Solo sem cobertura & 0,267 & 0,178 & $0,223 c$ \\
\hline \multirow[t]{2}{*}{ Média ${ }^{1}$} & $0,320 \mathrm{~A}$ & $0,255 \mathrm{~B}$ & \\
\hline & \multicolumn{3}{|c|}{ Diâmetro médio de cabeça $(\mathrm{cm}){ }^{* *}-\mathrm{CV}=9,66 \%$} \\
\hline Casca de café & 23,85 & 20,37 & $22,11 \mathrm{a}$ \\
\hline Casca de arroz & 20,41 & 16,44 & $18,43 b$ \\
\hline Capim braquiária seco & 19,93 & 15,70 & $17,82 b$ \\
\hline Plástico preto & 20,93 & 16,85 & $18,89 \mathrm{~b}$ \\
\hline Solo sem cobertura & 20,63 & 15,41 & $18,02 \mathrm{~b}$ \\
\hline \multirow[t]{2}{*}{ Média1 $^{1}$} & $21,15 \mathrm{~A}$ & $16,96 \mathrm{~B}$ & \\
\hline & \multicolumn{3}{|c|}{ Diâmetro médio de caule $(\mathrm{cm}) \mathrm{ns}$ - CV=10,90\% } \\
\hline Casca de café & 2,54 & 2,74 & $2,64 a$ \\
\hline Casca de arroz & 2,03 & 2,16 & $2,09 \mathrm{~b}$ \\
\hline Capim braquiária seco & 1,91 & 1,87 & $1,90 \mathrm{~b}$ \\
\hline Plástico preto & 2,16 & 2,00 & $2,08 \mathrm{~b}$ \\
\hline Solo sem cobertura & 2,04 & 1,69 & $1,87 \mathrm{~b}$ \\
\hline \multirow[t]{2}{*}{ Média $^{1}$} & $2,13 \mathrm{~A}$ & $2,09 \mathrm{~A}$ & \\
\hline & \multicolumn{3}{|c|}{ Número médio de folhas ${ }^{* *}-\mathrm{CV}=4,91 \%$} \\
\hline Casca de café & 32,93 & 27,89 & $30,41 \mathrm{a}$ \\
\hline Casca de arroz & 26,70 & 22,37 & $24,54 \mathrm{~b}$ \\
\hline Capim braquiária seco & 24,04 & 19,26 & $21,65 b$ \\
\hline Plástico preto & 27,85 & 20,45 & $24,15 b$ \\
\hline Solo sem cobertura & 26,07 & 20,82 & $23,45 \mathrm{~b}$ \\
\hline \multirow[t]{2}{*}{ Média1 $^{1}$} & $27,52 \mathrm{~A}$ & $22,16 \mathrm{~B}$ & \\
\hline & \multicolumn{3}{|c|}{ Massa média de raiz $(\mathrm{g})^{* *}-\mathrm{CV}=16,45 \%$} \\
\hline Casca de café & $15,44 \mathrm{aB}$ & $21,63 \mathrm{aA}$ & $18,54 \mathrm{a}$ \\
\hline Casca de arroz & $11,15 \mathrm{aB}$ & $15,55 \mathrm{bA}$ & $13,35 \mathrm{~b}$ \\
\hline Capim braquiária seco & $9,00 \mathrm{aA}$ & $12,51 \mathrm{bA}$ & $10,76 b$ \\
\hline Plástico preto & $12,52 \mathrm{aA}$ & $12,15 \mathrm{bA}$ & $12,34 \mathrm{~b}$ \\
\hline Solo sem cobertura & 12,48 aA & $10,22 \mathrm{bA}$ & $11,35 \mathrm{~b}$ \\
\hline Média1 & $12,12 \mathrm{~B}$ & $14,41 \mathrm{~A}$ & \\
\hline
\end{tabular}

**Significativo a $1 \%$ pelo teste $\mathrm{F}$; ${ }^{\text {ns}}$ não significativo; ${ }^{1}$ Médias seguidas por letras minúsculas nas colunas e por letras maiúsculas nas linhas não diferem entre si pelo teste de Scott e Knott. $(\alpha=0,05)$. 
mente dos tratamentos com plástico preto e casca de arroz. Os autores observaram que a temperatura média do solo coberto com casca de arroz foi igual a do solo sem cobertura, $23,9^{\circ} \mathrm{C}$, e as coberturas com plástico vermelho e preto foram as que propiciaram maiores temperaturas média do solo, $25,3{ }^{\circ} \mathrm{C}$ e $25,0^{\circ} \mathrm{C}$, respectivamente. Avaliando as cultivares de alface Brisa, Simpson, Verônica, Regina 579, Vera e Tainá, em diferentes coberturas de solo, (ZIZAS et al., 2002a), verificaram que a cultivar Regina 579 apresentou maior diâmetro do caule e maior número de folhas e que o uso de plásticos preto e vermelho resultou em menor massa média e produtividade por planta. Os autores relatam que estes resultados podem estar associados às ocorrências de maiores temperaturas do solo provocadas pela cobertura com estes plásticos em relação aos demais tipos de cobertura. Resultados semelhantes foram encontrados por Chaves et al. (2003) os quais relataram o efeito do plástico em aumentar a temperatura do solo a níveis de afetar o metabolismo da planta, interferindo no seu crescimento e desenvolvimento. Segundo Goto (1998), o uso de cobertura com plástico em alface deve ser avaliado para cada região de cultivo, uma vez que o aumento da temperatura do solo pode afetar o desenvolvimento de raízes e, por conseguinte, a absorção de nutrientes. Verdial et al. (2001) verificaram que a temperatura do solo coberto com plástico preto foi $25,12^{\circ} \mathrm{C}$, $1,56^{\circ} \mathrm{C}$ e $1,72^{\circ} \mathrm{C}$, respectivamente, maior que as temperaturas observadas para os tratamentos sem cobertura, sem capina e sem cobertura com capina quinzenal.

Um fator que deve ser considerado, embora não tenha sido avaliado, é a concentração e liberação de $\mathrm{K}$ da casca de café para o solo. Conforme relatam Guimarães et al. (2002), a casca de café contém alto teor de $\mathrm{K}$, em média 3,75 dag. $\mathrm{g}^{-1}$ de $\mathrm{K}_{2} \mathrm{O}$, sendo um resíduo da cafeicultura utilizado na adubação dos cafezais com o objetivo de repor o $\mathrm{K}$ extraído pelas plantas.

Segundo Rosolem et al. (2003) as espécies que acumularam $\mathrm{K}$ foram as que liberaram este elemento em maior quantidade. Sendo a casca de café rica em $\mathrm{K}$ pode-se afirmar que a superiori- dade da cobertura de canteiro com casca de café em relação aos demais tipos de cobertura pode estar relacionada à maior disponibilização de $\mathrm{K}$ para as plantas, contribuindo, conseqüentemente, para o melhor desenvolvimento das mesmas. Malavolta (1980) relata que mais de $80 \%$ do $\mathrm{K}$ encontra-se na forma solúvel na planta, sendo, portanto, passível de lixiviação.

A cultivar Regina foi superior à Elisa em produção total e comercial, massa média por planta, diâmetro médio de cabeça e número médio de folhas. Em média, a cultivar Regina apresentou produção total e produção comercial, 25,30\% e $28,57 \%$, maiores que a cultivar Elisa (Tabela 1). A massa média por planta e o diâmetro médio de cabeça da cultivar Regina foram $25,5 \%$ e $24,71 \%$, respectivamente, superior ao da cultivar Elisa. O número médio de folhas da cultivar Regina $(27,52)$ foi significativamente maior $(24,19 \%)$ que o da cultivar Elisa (22,16 folhas). Esses dados corroboram com os obtidos por Zizas et al. (2002b), em que a cultivar Regina apresentou maior número de folhas/planta e diâmetro de caule em relação à Elisa.

Não foi observada diferença significativa entre as cultivares para a característica diâmetro médio de caule (Tabela 1). Já a cultivar Elisa apresentou maior massa média de raiz, $(14,41 \mathrm{~g})$, em relação à Regina, $(12,12$ g), uma diferença de 18,89\%.

A interação significativa dos tipos de cobertura $x$ cultivares para a característica massa média de raiz (Tabela 1) mostra que para a cultivar Regina não foi observada diferença significativa entre os efeitos dos diferentes tipos de cobertura de canteiro. Já para a cultivar Elisa, a cobertura com casca de café foi superior às médias dos demais tratamentos, em 71,53\%, tendo a mesma proporcionado 21,63 g de massa média de raiz. Observou-se que a cultivar Elisa apresentou maior massa média de raiz quando foram utilizadas as coberturas com casca de café e casca de arroz, respectivamente, $40,09 \%$ e $39,46 \%$. Não foram observadas diferenças significativas entre cultivares para os demais tipos de cobertura de canteiro.

A diferença significativa do fator cultivar é esperada, pois a produção de uma cultivar é função de seu genótipo e da interação genótipo $\mathrm{x}$ ambiente (QUEIROGA et al., 2001; SILVA et al., 2000).

Conclui-se que a cobertura de canteiro com casca de café proporcionou o melhor crescimento e desenvolvimento da alface. Entre as cultivares, a Regina foi superior à Elisa quanto às características de produção total, produção comercial, massa média por planta, diâmetro médio de cabeça e número médio de folhas. Entretanto, a cultivar Elisa apresentou maior massa média de raiz em relação à Regina. A maior massa média de raiz da cultivar Elisa não influenciou as demais características avaliadas, baseando-se na hipótese de que uma maior massa média de raiz proporcionaria maiores produção total e comercial, massa média por planta, diâmetro médio de cabeça e do caule e maior número médio de folhas, por explorar melhor o solo, e consequentemente, absorver mais água e nutrientes. Este fato pode estar relacionado a maior eficiência da cultivar Regina em absorver água e nutrientes, pois esta foi superior à Elisa para a maioria das características avaliadas. Em termos de massa média de raiz, a cultivar Elisa apresentou melhores resultados quando as coberturas de canteiros utilizadas foram casca de café e casca de arroz.

\section{LITERATURA CITADA}

ANDREANI JÚNIOR, R.; GALBIATI NETO, P. Avaliação da influência de coberturas mortas sobre o desenvolvimento da cultura da alface na região de Fernandópolis-SP. Horticultura Brasileira, Brasília, v.21, n.2, Julho, 2003. Suplemento 2, CD-ROM. Trabalho apresentado no $43^{\circ}$ Congresso Brasileiro de Olericultura, 2003.

ARAÚJO, R.C.; SOUZA, R.J.; SILVA, A.M.; ALVARENGA, M.A.R. Efeitos da cobertura morta do solo sobre a cultura do alho (Allium sativum L.). Ciência e Prática, Lavras, v.17, n.3, p.228233, 1993.

CASTELLANE, P.D.; SOUZA, A.F.; MESQUITA FILHO, M.D. Culturas olerícolas. In: FERREIRA, M.E. CRUZ, M.C.P. (eds). Micronutrientes na agricultura. Piracicaba: POTAFOS/ CNPq, 1995, p.549-584.

CHAVES, S.W.P.; MEDEIROS, J.F.; NEGREIROS, M.Z.; NAGÃO, E.O. Rendimento de alface em função da cobertura do solo e frequiência de irrigação. Horticultura Brasileira, Brasília, v.21, n.2, Julho, 2003. Suplemento 2, CD-ROM. Trabalho apresentado no $43^{\circ}$ Congresso Brasileiro de Olericultura, 2003.

FERREIRA, D.F. Sisvar - Sistema de análise de 
variância para dados balanceados. Versão 4.0 (Build 34). Lavras: DEX/UFLA, 1999. (Software Estatístico)

GOTO, R. A cultura da alface. In: GOTO, R. TIVELLI, W.S. Produção de hortaliças em ambiente protegido: condições subtropicais. São Paulo: Fundação Editora da UNESP, 1998. p.137-159. GUIMARÃES, P.T.G.; NOGUEIRA, F.D.; LIMA P.C.; GUIMARÃES, M.J.C.L.; POZZA, A.A.A Adubação e nutrição do cafeeiro em sistema orgânico de produção. Informe Agropecuário, Belo Horizonte, v.23, n.214/215, p.63-81, 2002.

MAIA NETO, J.M. Efeito da cobertura morta sobre o comportamento de cultivares de alface (Lactuca sativa L.) no município de Mossoró. Mossoró, 1988, 16 p. (Coleção Mossoroense, série $\left.\mathrm{B}, \mathrm{n}^{\circ} 515\right)$.

MALAVOLTA, E.A. Elementos de nutrição mineral de plantas. São Paulo: Agronômica Ceres, 1980. $251 \mathrm{p}$.

QUEIROGA, R.C.F.; BEZERRA NETO, F. NEGREIROS, M.Z.; OLIVEIRA, A.P.; AZEVEDO, L.M.S.B. Produção de alface em função de cultivares e tipos de tela de sombreamento nas condições de Mossoró. Horticultura Brasileira, Brasília, v.19, n.3, p.324-328, 2001.

QUEIROGA, R.C.F.; NOGUEIRA, I.C.C.; BE-
ZERRA NETO, F.; MOURA, A.R.B.; PEDROSA, J.F. Utilização de diferentes materiais como cobertura morta do solo no cultivo de pimentão.

Horticultura Brasileira, Brasília, v.20, n.3, p.416418, 2002.

REGHIN, M.Y.; PURISSIMO, C.; DALLA PRIA M.; FELTRIM, A.L.; FOLTRAN, M.A. Técnicas de cobertura do solo e de proteção de plantas no cultivo da alface. Horticultura Brasileira, Brasília, v.20, n.2, Julho, 2002, Suplemento 2. CD-ROM. Trabalho apresentado no $42^{\circ}$ Congresso Brasileiro de Olericultura, 2002

ROBINSON, D.W. Mulches ornamental plantings. Author's reply. Hortscience, v.23, n.6, 1988. ROSOLEM, C.A.; CALONEGO, J.C.; FOLONI, J.S.S. Lixiviação de potássio da palha de espécies de cobertura de solo de acordo com a quantidade de chuva aplicada. Revista Brasileira de Ciência do Solo, Viçosa, v.27, p.355-362, 2003.

SILVA, V.F.; BEZERRA NETO, F.; NEGREIROS, M.Z.; PEDROSA, J.F. Comportamento de cultivares de alface em diferentes espaçamentos sob temperatura e luminosidade elevados. Horticultura Brasileira, v.18,n.3, p.183-187, 2000. VERDIAL, M.F.; LIMA, M.S.; MORGOR, A.F.;
GOTO, R. Production of iceberg lettuce mulches Scientia Agrícola, v.58, n.4, p.737-740, 2001.

ZIZAS, G.B.; SENO, S.; FARIA JÚNIOR, M.J.A.; SELEGUINI, A. Efeito da cobertura do solo sobre a produtividade e qualidade de 6 cultivares de alface e das interações solo/cultivar, no período de maio a junho de 2001. Horticultura Brasileira, Brasília, v.20, n.2, Julho, 2002. Suplemento 2. CD-ROM. Trabalho apresentado no $42^{\circ}$ Congresso Brasileiro de Olericultura, 2002b.

ZIZAS, G.B.; SENO, S.; FARIA JÚNIOR, M.J.A.; SELEGUINI, A. Interação de cultivares e cobertura do solo na produção e qualidade de alface (período de março a abril de 2001). Horticultura Brasileira, Brasília, v.20, n.2, Julho, 2002. Suplemento 2. CD-ROM. Trabalho apresentado no $42^{\circ}$ Congresso Brasileiro de Olericultura, 2002a. 